\title{
Evaluation of Concretes Made with Marble Waste Using Destructive and Non-Destructive Testing
}

\author{
Messaouda Belouadah ${ }^{1}$, Zine Elabidine Rahmouni $^{1}$, Nadia Tebbal ${ }^{2}$, Mokrani El Hassen Hicham $^{1}$ \\ ${ }^{1}$ Laboratory for Geo-Materials Development, Civil Engineering Department, Faculty of Technology, Msila University, M'sila \\ 28000, Algeria \\ ${ }^{2}$ Institute of Urban Techniques and Management, Msila University, M'sila 28000, Algeria
}

Corresponding Author Email: messaouda.belouadah@univ-msila.dz

https://doi.org/10.18280/acsm.450501

Received: 13 September 2021

Accepted: 12 October 2021

\section{Keywords:}

concrete, marble powder, mechanical strength, destructive testing, durability, non-destructive testing, super plasticizer

\begin{abstract}
The present study aims primarily to investigate the possibility of assessing the physicomechanical behavior of concrete incorporating marble waste or marble powder as a partial replacement for cement using destructive and non-destructive testing methods. Indeed, in this work, cement was partially replaced with marble powder at six different substitution levels, i.e. $5,10,15,20,25$ and $30 \%$ by weight, with $1.5 \%$ adjuvant (super plasticizer) for each mixture. The samples prepared were then analyzed. In addition, the physico-mechanical properties, in the fresh and hardened states, water-to-cement ratio, absorption and compressive strengths of the concrete samples were examined as well. Moreover, the compressive strength of concrete was assessed through non-destructive testing methods such as the ultrasonic pulse velocity and rebound hammer. Likewise, the relationship between the ultrasound velocity and compressive strength of concrete were also estimated after 3, 7, 28 and 90 days of curing. The findings of the study indicated that, at early age of curing, the values of the compressive strength and ultrasonic pulse velocity were quite small for all replacement levels, of cement with marble powder, between 15 and 30\%. Nevertheless, when the curing period was increased, the compressive strength and ultrasonic pulse velocity of all the samples went up as well. In the end, a linear relationship was observed between the ultrasonic pulse velocity and compressive strength for all substitution levels of cement with marble powder.
\end{abstract}

\section{INTRODUCTION}

Throughout It is widely admitted that the mechanical properties of concrete can be estimated using destructive as well as non-destructive testing methods $[1,2]$. It should be mentioned that crush testing of concrete samples is a destructive testing approach. In general, the rebound hammer (RH) test and the ultrasonic pulse velocity (UPV) test are utilized as concrete testing procedures to carry out nondestructive tests. Indeed, a large number of non-destructive tests (NDTs) are ordinarily conducted on concrete structures for the purpose of assessing the compressive strength of concrete and other related characteristics. It is widely acknowledged that many of these tests are quite efficient in evaluating the damage that could occur in concrete structures subjected to overloading, aging, corrosion, chemical attacks, etc. Today, it has become highly urgent to develop an efficient tool for early and regular assessment of a concrete structure in order to determine its structural safety, durability and performance levels. In this context, innovative NDT approaches can be utilized for the structural assessment of many actual concrete constructions; however, they have not yet been accepted and confirmed for standard inspections [3]. It is worth indicating that the purpose of applying conventional methods for non-destructive testing (NDT) of concrete structures is to assess the properties of in-situ concrete material without examining the material itself. It should be mentioned that a number of non-destructive testing (NDT) techniques are presently used for research purposes. Indeed, many researchers attempted to establish standard NDT procedures that can widely be used in the field. In the present study, the rebound hammer (RH) and ultrasonic pulse velocity (UPV) tests were used to perform some non-destructive tests (NDTs) on marble powder-based concrete.

It is certainly acknowledged that waste generation has become a serious problem that has been affecting the majority of countries throughout the world. Note that, for instance, over the past few years, construction and mining industry have engendered about 1566 million tons of wastes each year, which represents more than half the total quantity of wastes that were generated in European countries during the year 2016. Moreover, the increasing number of new construction projects requires more and more raw materials to be extracted in order to meet the growing demands for concrete [3, 4]. In addition, it is worth recalling that the main component of concrete is cement. Recently, limestone and gypsum, which are widely used in concrete, have witnessed an extraction increase, particularly during the year 2016; the total quantity extracted was estimated at 594 million tons. Likewise, marble and granite were also significantly mined from quarries. Indeed, 637 million tons of raw marble and granite were excavated in the year 2016. It should be noted that the large quantities of marble and granite wastes, which are engendered through mining extraction, ought to be taken away and laid in 
adequate places. Today, highly efficient processes are urgently needed for the control and management (transportation, storage, and disposal) of wastes which have a considerably detrimental impact on the environment. Over the past few decades, it has been found that these wastes can eventually be used in various industrial applications. In the recent past, a large number of researchers became interested in the valorization of mineral wastes, which proved to be significantly harmful for the environment and living beings [5, 6]. They found out that these wastes can indeed be incorporated in the formulation of cementitious materials. From the environmental and economic points of view [5], the recycling of wastes can be of major importance. In this context, marble powder (MP), which is one of these mineral wastes, was used in this study as a partial substitution for cement to make concrete. Indeed, replacing cement with marble powder allows reducing the use of gypsum and limestone and, at the same time, helps getting rid of significant amounts of marble waste from the environment. For these reasons, a lot of research efforts have been devoted to developing and assessing the eventuality of incorporating waste marble powder in mortars and concretes. The compressive strength and workability results were compared with those of control concrete samples incorporating conventional cement and natural sand. A large number of studies reported in the literature, about using marble powder (MP) as a cement substitution in cementitious materials, and based on destructive tests, arrived at the conclusion that marble powder can effectively enhance the freshest and most hardened properties, as well as the durability, of the formulated cementitious materials [7-9]. For instance, it was found that incorporating waste marble powder, instead of ordinary aggregates, in the preparation of concrete allows increasing its compressive strength. Similarly, it turned out also that waste marble, as opposed to coarse aggregates, helps to improve the workability of these cementitious materials. However, when fine aggregates were replaced with waste marble, their workability went down. In addition, the incorporation of waste marble powder in the preparation of concrete led to a $12 \%$ decline in carbon dioxide emissions and the concrete cost dropped from $\$ 40 / \mathrm{m}^{3}$ to $\$ 33 / \mathrm{m}^{3}$ [9]. More importantly, it turned out that employing marble powder as a partial replacement component up to $20 \%$ by volume in the formulation of concrete allowed enhancing its physical and mechanical properties [10].

On the other hand, some researchers indicated that the optimal waste marble ratio for the replacement of fine aggregates in a cementitious mixture was estimated at $10 \%$. In addition, a number of studies were carried out on the incorporation of marble powder in cementitious materials using non-destructive tests (NDTs), such as the ultrasonic pulse velocity (UPV) test, porosity test, and compressive strength test [11], to investigate the effect of including waste marble powder as fine sand on the mechanical properties of the formulated concrete. The findings suggested that the ultrasonic pulse velocity (UPV) was improved as the marble dust replacement ratio increased. Additional studies $[4,8]$ indicated that employing marble powder as a partial replacement for cement or sand did not have a significant effect on the UPV values of concrete. It is worth indicating that a large number of studies carried out non-destructive testing (NDT) methods to investigate the properties of concrete containing marble powder (MP) as a partial replacement for cement. However, as far as we know, no studies have been conducted to assess the effect of using the ultrasonic pulse velocity (UPV) and rebound hammer (RH) tests on the behavior of cementitious materials incorporating marble powder (MP) as a partial replacement for cement, under various water curing conditions. For all these reasons, it was deemed interesting to pursue this research work to assess the effects of using the UPV and RH non-destructive tests on the mechanical properties of the formulated cementitious materials. Indeed, both the destructive and non-destructive testing methods were applied for the purpose of corroborating the experimental data that were recorded from the destructive tests. In addition, an empirical relationship between the nondestructive and destructive tests was developed so as to predict the mechanical and physical characteristics of cement paste and concrete incorporating marble powder.

\section{EXPERIMENTAL PROGRAM}

\subsection{Materials}

In this research work, the Portland cement type CEM II/A 42.5, from Hammam Dalâa cement plant in the Wilaya of Msila, was employed. It should be noted that the absolute density, bulk density, porosity, and Blaine specific surface area were respectively equal to $3.1 \mathrm{~g} / \mathrm{cm}^{3}, 1.9 \mathrm{~g} / \mathrm{cm}^{3}, 41.93 \%$ and $4000 \mathrm{~cm}^{2} / \mathrm{g}$. In addition, the chemical and mineralogical compositions of this cement are summarized in Table 1.

Table 1. Chemical and mineralogical composition of cement and marble powder

\begin{tabular}{|c|c|c|c|c|c|c|}
\hline \multicolumn{6}{|c|}{ Chemical composition of cement and marble powder (\%) } & \\
\hline \multicolumn{2}{|c|}{ Element } & \multicolumn{2}{|c|}{$\mathrm{C}$} & \multicolumn{2}{|l|}{ MP } & \\
\hline \multicolumn{2}{|l|}{$\mathrm{SiO}_{3}$} & \multicolumn{2}{|l|}{27.77} & \multicolumn{2}{|l|}{1.47} & \\
\hline $\mathrm{Al}_{2} \mathrm{O}_{3}$ & \multicolumn{3}{|c|}{7.00} & \multicolumn{2}{|l|}{0.35} & \\
\hline $\mathrm{Fe}_{2} \mathrm{O}_{3}$ & \multicolumn{3}{|c|}{2.29} & \multicolumn{2}{|l|}{0.14} & \\
\hline $\mathrm{CaO}$ & \multicolumn{3}{|c|}{56.91} & \multicolumn{2}{|l|}{55.30} & \\
\hline $\mathrm{MgO}$ & \multicolumn{3}{|c|}{3.38} & \multicolumn{2}{|l|}{0.01} & \\
\hline $\mathrm{SO}_{3}$ & \multicolumn{3}{|c|}{2.30} & \multicolumn{2}{|l|}{0.01} & \\
\hline $\mathrm{Na}_{2} \mathrm{O}$ & \multicolumn{3}{|c|}{0.12} & \multicolumn{2}{|l|}{0.12} & \\
\hline $\mathrm{K}_{2} \mathrm{O}$ & \multicolumn{3}{|c|}{0.51} & \multicolumn{2}{|l|}{0.04} & \\
\hline Loss on ignition & \multicolumn{3}{|c|}{2.73} & \multicolumn{2}{|l|}{42.56} & \\
\hline$\Sigma$ & \multicolumn{3}{|c|}{100} & \multicolumn{2}{|l|}{100} & \\
\hline \multicolumn{6}{|c|}{ Mineralogical composition of cement $(\%)$} & \\
\hline Constituents & & $\mathrm{C}_{3} \mathrm{~S}$ & $\mathrm{C}_{2} \mathrm{~S}$ & $\mathrm{C}_{3} \mathrm{~A}$ & $\mathrm{C}_{4} \mathrm{AF}$ & \\
\hline$(\%)$ & & $58-64$ & $12-18$ & $6-8$ & $10-12$ & \\
\hline \multicolumn{7}{|c|}{ Mineralogical composition of marble powder (\%) } \\
\hline Elements & Calcite & Dolomite & Quartz & Illite & Chlorite & Kaolinite \\
\hline$(\%)$ & 98.55 & 0.14 & 0.12 & 0.11 & 0.39 & 0.68 \\
\hline
\end{tabular}


It is worth specifying that the waste marble powder (MP) utilized in this research was supplied by the manufacturing plant of marble in the region of Bou Saâda (Algeria). In addition, the physical and chemical characteristics of marble powder are presented in Table 1 and Table 2.

Furthermore, the dune sand (S), which was brought from the region of Bou Sâada (Algeria), was utilized as natural fine aggregates with particle sizes ranging from 0.08 to $5 \mathrm{~mm}$. The fineness modulus was equal to 2.08 . In addition, the absolute density and porosity were estimated at $2.58 \mathrm{~g} / \mathrm{cm}^{3}$ and $42.96 \%$, respectively. Moreover, the sieve analysis or gradation analysis was performed in accordance with the European Standard NF EN 933-1.

In the present work, locally available coarse aggregates (Gr), with maximum sizes between $8 \mathrm{~mm}$ and $16 \mathrm{~mm}$, were used. These aggregates were first washed to eliminate all impurities, and then dried until water was completely removed from their surface. They were next tested according to the standard NF EN 933- 1.

Further, the adjuvant employed is the Medaplast SP40 High Range Water Reducing Super plasticizer which was used in a solution of $\mathrm{pH}=8.2$ and of density $=1.22$, and containing $40 \%$ of solids, Chlorine Content $\leq 1 \mathrm{~g} / \mathrm{l}$. Its range of normal use, as fixed by the manufacturer's recommendations, is between 0.6 and $2.5 \%$ of the cement weight. Moreover, the chemical admixture content was $1.5 \%$ of cement's weight, for all mixes. The characteristics of the adjuvants were collected from the technical data sheet provided by the manufacturer [12]. Properties of MEDAPLAST SP 40 are:

\begin{tabular}{ccc}
\hline designation & \multicolumn{2}{c}{ Rc (MPa) } \\
\hline Days & 7 days & 28 days \\
concrete test & 8.05 & 31.3 \\
MEDAPLAST SP 40 (1.5\%) & 13.65 & 38.13 \\
\hline
\end{tabular}

Table 2. Physical properties of $\mathrm{C}$ and MP

\begin{tabular}{ccc}
\hline Properties & C & MP \\
\hline Volume expansion: $\mathrm{mm}$ & 1.50 & - \\
Initial setting time: $(\mathrm{min})$ & 181 & - \\
Final setting time: $(\mathrm{min})$ & 254 & - \\
Specific gravity: $\left(\mathrm{g} / \mathrm{cm}^{3}\right)$ & 3.1 & 2.70 \\
Specific surface: $\left(\mathrm{cm}^{2} / \mathrm{g}\right)$ & 4000 & 7500 \\
Bulk density $\left(\mathrm{g} / \mathrm{cm}^{3}\right)$ & 1.21 & 0.98 \\
\hline
\end{tabular}

Table 3. Chemical properties of the water

\begin{tabular}{cc}
\hline The measure & Content (mg/l) \\
\hline Temperature degree & 24.7 \\
PH & 7.78 \\
Conductivity & 1799 \\
Chlorine $\mathrm{Cl}^{-}$ & 234.3 \\
Sulphate $\mathrm{So}^{-4}$ & 351.6 \\
Water oxidation re-eligibility & 1024 \\
magnesium $\mathrm{Mg}^{2+}$ & 110.8 \\
Sodium $\mathrm{Na}^{+}$ & $/$ \\
Calcium $\mathrm{Ca}^{2+}$ & 267.2 \\
Dry sediment & 1412 \\
\hline
\end{tabular}

Water (W) is an essential constituent in concrete mixtures because it plays a very important role and takes part in various chemical reactions with cement. Therefore, the quantity and quality of water used must be taken into account more carefully and more seriously because this can certainly help to improve the compressive strength of the formulated concrete. It should be indicated that local potable tap water does not contain any harmful products, and was therefore employed for concrete mixing all through this work. The chemical analysis of the water used was carried out in the chemistry laboratory (Media) are shown in Table 3.

\subsection{Mixture proportioning}

A pan mixer of capacity $30 \mathrm{~L}$ was utilized for the preparation of concrete mixtures with and without marble powder are shown in Figure 1. The concrete mix design, which is based on the Dreux-Gorisse method, was proposed for the preparation of control concrete. Cement was replaced by marble powder at the proportions of $0,5,10,15,20,25$ and $30 \%$ in the formulation of the concrete mixtures to be examined. The prepared concrete specimens were stored in their molds at a temperature of $20^{\circ} \mathrm{C}$ and $95 \%$ relative humidity (RH), for a period of 24 hours. After demolding, they were immersed in water at $20^{\circ} \mathrm{C}$ until the age of testing. Afterwards, the physical and mechanical characteristics of concrete, with and without marble powder, were compared. The final compositions of concrete mixtures without and with addition, after optimization, are reported in Table 4 [8].

Table 4. Compositions of concrete with and without MP

\begin{tabular}{|c|c|c|c|c|c|c|}
\hline Mixes & $\underset{\mathrm{kg} / \mathrm{m}^{3}}{\mathrm{C}}$ & $\begin{array}{c}\text { MP \% } \\
\text { by } \\
\text { cement } \\
\text { weight }\end{array}$ & $\begin{array}{l}\mathrm{W} \\
\mathbf{k g} \\
/ \mathrm{m}^{3}\end{array}$ & $\underset{\mathrm{kg} / \mathrm{m}^{3}}{\mathrm{~S}}$ & $\begin{array}{c}\text { Gr } \\
(3 / 8) \\
\text { kg/m }\end{array}$ & $\begin{array}{c}\text { Gr } \\
(8 / 15) \\
\text { kg/m }\end{array}$ \\
\hline Mix0 & 350 & 0 & & & & \\
\hline Mix1 & 332.5 & 5 & & & & \\
\hline Mix2 & 315 & 10 & & & & \\
\hline Mix3 & 297.5 & 15 & 215.4 & 651.9 & 142.7 & 968.9 \\
\hline Mix4 & 280 & 20 & & & & \\
\hline Mix 5 & 262.5 & 25 & & & & \\
\hline Mix 5 & 245 & 30 & & & & \\
\hline
\end{tabular}

The following acronyms will be used henceforth:

- Mix0: Reference concrete;

- Mix 1: Concrete with 5\% marble powder and 1.5\% (by weight of cement) of admixture;

- Mix2: Concrete with 10\% marble powder and 1.5\% (by weight of cement) of admixture;

- Mix3: Concrete with 15\% marble powder and 1.5\% (by weight of cement) of admixture;

- Mix4: Concrete with 20\% marble powder and $1.5 \%$ (by weight of cement) of admixture;

- Mix 5: Concrete with 25\% marble powder and 1.5\% (by weight of cement) of admixture;

- Mix6: Concrete with 30\% marble powder and 1.5\% (by weight of cement) of admixture.

It is worth mentioning that the workability of all the formulated concretes was measured by the Abrams cone slump test, in accordance with the study [13].

This characteristic was determined using cylindrical concrete specimens, with a diameter of $10 \mathrm{~cm}$ and height of $12 \mathrm{~cm}$, placed in contact with free water to a constant height of $1 \mathrm{~cm}$. The side faces were coated with a self-adhesive aluminum foil in order to force water to move along the axis of the sample and to prevent evaporation [14] through the lateral faces. It should be noted that the mass of water absorbed could be determined by successively weighing the samples at different dates. It is important to make sure that the film of water retained on the underside of the sample is removed 
before each weighing, using absorbent paper.

On the other hand, it is worth specifying that the rebound hammer (RH) test is a non-destructive testing method for concrete; it is founded on the precept that the elastic mass rebound depends on the hardness of the concrete surface this mass strikes. The functioning principle of the rebound hammer $(\mathrm{RH})$ is clearly displayed in Figure 2a. Indeed, when the plunger of the rebound hammer is pressed against the concrete surface, the spring-driven mass in the hammer hits that surface and rebounds back. The height to which the spring-controlled mass rebounds depends on the concrete surface hardness. It was found that the concrete hardness and rebound hammer reading are correlated with the compressive strength of concrete. Obviously, the rebound value may directly be read from a calibrated scale; it is called the rebound number or rebound index. Moreover, the compressive strength can be directly registered from the graph given on the hammer. It should be noted that all measurements were performed according to standard [15].

On the other hand, the ultrasonic pulse velocity (UPV) test, which is part of the non-destructive testing procedure, was used to evaluate the time necessary for a sound wave to go through a known concrete thickness in order to find its velocity. All measurements were performed in accordance with Standard (ASTM C597-02) using the Pundit pulse velocity ultrasonic device Figure $2 b$.

With regard to the compressive strength of concrete, it was assessed on cube specimens $(100 \mathrm{~cm})$ at the ages of $7,14,28$ and 90 days, using a $3000 \mathrm{KN}$ capacity testing machine, in accordance with the study [16]. The final compressive strength value was taken as the average of the values recorded for three specimens.

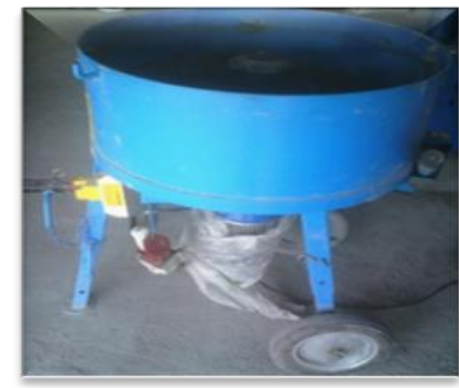

Figure 1. Mixer used
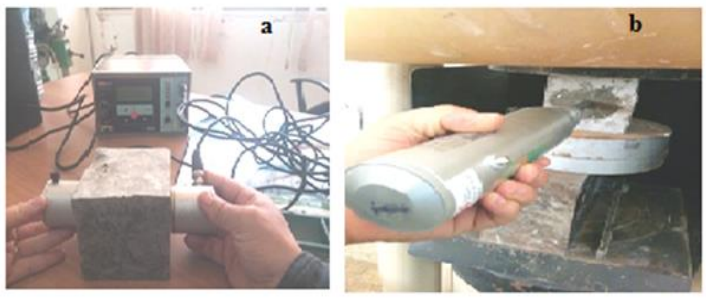

Figure 2. Non-destructive tests (a) Ultrasonic pulse velocity tester; (b) Sclerometer hardness tester

\section{RESULTS AND DISCUSSION}

\subsection{Effect of marble powder content on the ratio (W/C)}

Figure 3 illustrates the variation of the water-to-cement $(\mathrm{W} / \mathrm{C})$ ratio as a function of the marble powder content in fresh concrete mixtures.

In Figure 3, one can see the water-to-cement (W/C) ratio values that are required for the preparation of concrete incorporating marble powder (MP) at dosages ranging from $5 \%$ to $30 \%$ of cement weight, for the different concrete mixtures. It was noted that the workability of concrete decreased as the marble content increased. Therefore, it may be said that, for all concrete types, when the marble powder content increases, the amount of mixing water diminishes. This can certainly be attributed to the primary cohesion forces between the particle aggregates.

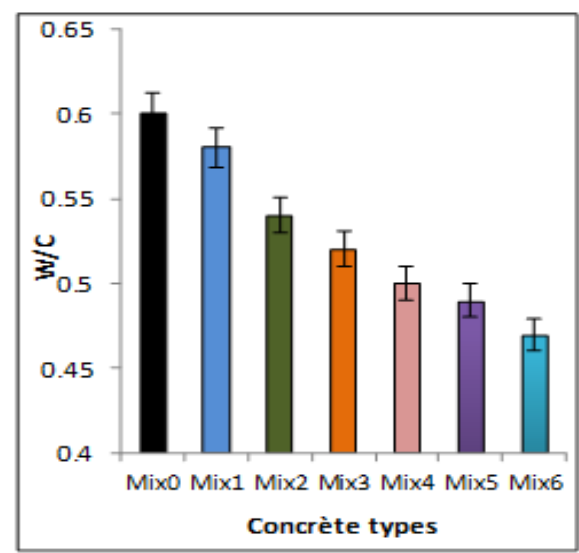

Figure 3. Effect of marble powder content on the ratio (W/C)

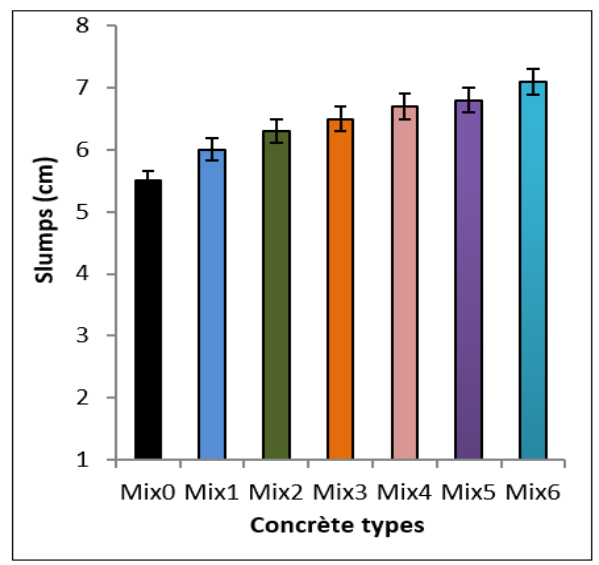

Figure 4. Variation of slump of concrete with cement replacement by marble powder

Furthermore, the loss of concrete consistency can reach $17 \%$ with respect to that of reference concrete Mix 0 . These findings are in agreement with those reported by Rao [10]. On the other hand, it is worth knowing that the inclusion of the high range water-reducing admixture $(1.5 \%$ of Medaplast SP40) causes a considerable reduction in the amount of mixing water, for all concrete types, in spite of the high marble powder contents. It should also be mentioned that the chemical admixture (super plasticizer) was used for deflocculating the fine particles of cement, which caused the compactness of the mixture to increase, and at the same time for lubricating the solid particle surfaces and therefore reducing friction between particles [8].

Furthermore, the experimental results, illustrated in Figure 4 , suggest that the incorporation of mineral additions into the concrete mixtures had a negative impact on the workability of concrete. Indeed, it was revealed that when the marble powder 
content increased (i.e. cement content decreased), the workability dropped. Note that the increase in the marble content caused a reduction in the fineness modulus of the cementitious material. Therefore, the amount of cement paste available became insufficient to provide a lubricating effect per unit area of the aggregates. This would limit their mobility [17].

\subsection{Effect of marble powder on the capillary water absorption}

Figure 5 depicts the variation of capillary water absorption of concrete as a function of the percentage contents of marble powder.

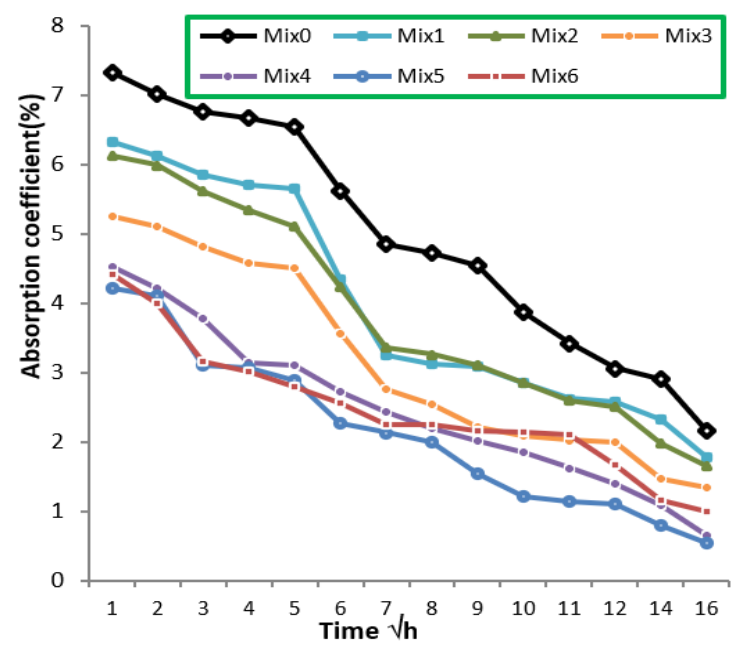

Figure 5. Capillary water absorption coefficients of concretes

It was found that the water absorption capacity (sorptivity coefficient) of concretes incorporating marble powder and admixture (superplasticizer) is generally lower than that of control concrete. In this context, Mix 1 concrete was found to have a water absorption capacity comparable to that of control concrete $(6 \%)$. These results have previously been confirmed by other researchers [18]. In addition, a decrease in the water absorption capacity values for mixtures Mix 3 and Mix 4 was noted when the replacement rate of cement with marble powder went up, while using the percentage content of $1.5 \%$ of super plasticizer in the formulation of our concrete preparations. It can therefore be concluded that the inclusion of marble powder and super plasticizer has a positive effect on concrete because the water absorption of the formulated concrete decreases. The lowest water absorption value was recorded for Mix 4, with a 35\% reduction as compared to that of Mix0 (control concrete). These findings may certainly be attributed to the fact the fine marble powder aggregates filled the voids within the cement matrix, which caused the concrete porosity to diminish.

Furthermore, it was found that the water absorption capacity of concrete decreased as the amount of marble powder increased in the concrete mixture; this may be attributed to the density and porosity increases in the formulated concretes [19]. It should also be noted that the concrete porosity is influenced by the packing characteristics of the entire concrete mixture which includes fine aggregates, cement, and water. In addition, one can observe that the water absorption values of mixture Mix 5 are lower (3.25\%) than those of Mix1 concrete $(6 \%)$.
Further, using the chemical admixture (1.5\% of Medaplast SP 40) allows reducing the number of voids within the concrete mixture, which consequently makes it more compact, more resistant, and more impervious to water. This can surely be assigned to the fact that the fine marble powder has a lower pore size distribution in comparison with that of control concrete. In addition to their high compressive strength, the durability of the concrete samples was also improved.

\subsection{Effect of marble powder on the mechanical strength of concrete}

Note that the compressive strength values of the different concrete types with and without marble powder at 7, 14, 28, and 90 days, are depicted in Figure 6.

It is also interesting to note, from the previous figures, that the compressive strength of all concrete types increased with age.

Indeed, after 7 days, the compressive strength reached almost $60 \%$ of the value obtained at 28 days; in this case the $10 \%$ replacement rate of cement with marble powder contributed to increasing the average strength of concrete in comparison with that of control concrete. Moreover, the concrete compressive strength increase over time, for all concrete compositions, was certainly due to the hydration of $\mathrm{C} 3 \mathrm{~S}$ in the presence of $\mathrm{CaCO}_{3}$ present in marble powder. This hydration reaction would produce calcium hydrates which had a positive impact on the mechanical properties of concrete [20].

It is worth indicating that there are chemical-type forces, beside the Van Der Waals forces, that ensure cohesion between the cement paste and limestone aggregates [20]. In addition, it was revealed that the fineness of additions and their substitution rates had a positive effect on the compressive strength of the formulated concrete. The compressive strength increase can therefore be explained by the high compactness of the specific surface area of the large amounts of marble in the mixture. It should be noted that the optimal composition was obtained with $10 \%$ of marble powder, with a specific surface area equal to 7000 , in addition to $1.5 \%$ super plasticizer. These findings corroborate those reported in other research works $[21,22]$.

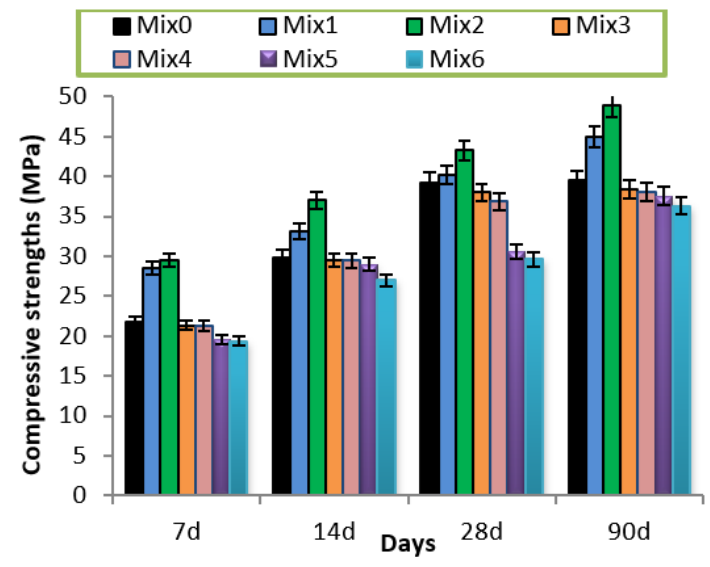

Figure 6. Evolution of the compressive strength of concrete over time

\subsection{Influence of marble powder dosage on the ultrasonic pulse velocity}

A large number of studies have been carried out on the 
effect of marble powder dosage on the ultrasonic pulse velocity in concrete $[23,24]$.

Figure 7 clearly illustrates the evolution and development of the speed of sound within different types of concrete according to their age, i.e. 7,14 , and 28 days. It should be noted that all concretes containing fillers generally exhibit a normal speed of sound, which is not the case for control concrete (Mix0). It is therefore worth noting that for:

- Concrete Mix 0, the ultrasonic pulse speed values are smaller than those obtained in other concretes $(3.38 \mathrm{~km} / \mathrm{s}, 4.10$ $\mathrm{km} / \mathrm{s}$ and $4.45 \mathrm{~km} / \mathrm{s}$ at 7, 14, 28 days, respectively).

- Concrete Mix 4, the ultrasonic pulse velocity is slightly lower $(3.28 \mathrm{Km} / \mathrm{s}, 3.94 \mathrm{Km} / \mathrm{s}, 4.48 \mathrm{Km} / \mathrm{s}$ at 7, 14, and 28 days, respectively) than those recorded in Mix0; the difference is around $2 \%$ at 28 days. Figure 7 clearly indicates that the ultrasonic pulse velocity (UPV) in concrete at 7, 14 and 28 days, increased as the substitution rate of cement with marble dust powder approached $10 \%$. This may certainly be attributed to the inclusion of this inert MP addition, because when these ultrafine aggregates fill the voids in concrete, the cement paste-aggregate interfacial transition zone is automatically improved $[4,25]$. Consequently, if the replacement percentage of cement with marble dust powder increases, the ultrasonic pulse velocity of concrete decreases. This can be explained by the significant decrease in the clinker content of the cement mixture.

Note that the UPV decline resulted from the decrease in density. In this case, the ultrasonic pulse needed a longer time to go through the length of the solid material [26]. Moreover, this UPV diminution could also have resulted from the porosity increase due to the decrease in hydrate products resulting from the utilization of marble powder in concrete $[8$, 24]. It should also be noted that the ultrasonic pulse velocity of concrete was improved by $16.76 \%$ and $21.82 \%$ at 7 and 28 days, respectively.

Furthermore, the ultrasonic pulse velocity testing method was also applied to check the homogeneity and quality of concrete. This technique uses the propagation of highfrequency sound waves through concrete in which the speed of ultrasonic waves depends on the density of the material. Indeed, once the marble powder is incorporated as cement replacement, at early age, the concrete porosity and the time needed by high-frequency sound waves to pass through the material, both augments.

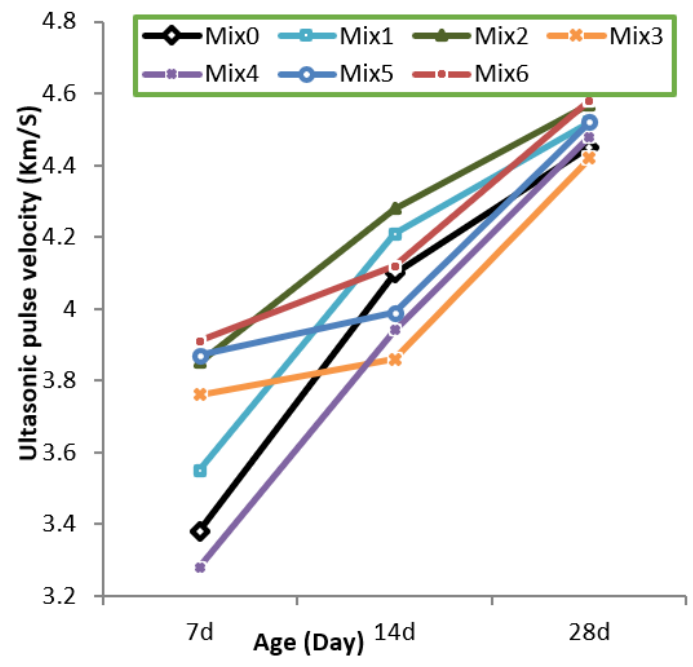

Figure 7. Ultrasonic pulse velocities for different types of concrete
3.5 Relationship between the ultrasonic pulse velocity and compressive strength of concrete

The data reported in Figure 8 show explicitly the ultrasonic pulse velocity augmented as the age of the concrete increased, which was logically expected. In addition, it was also revealed that the UPV values of concrete increased with its compressive strength. A simple comparison shows that a strong correlation of 0.8719 was observed between the UPV and the compressive strength of concrete. This very strong direct correlation is clearly illustrated in Figure 7. Moreover, the results of the ultrasonic pulse velocity test, during the first week, allowed observing that the UPV values obtained were relatively high in comparison with those recorded during the remaining period of study.

Figure 8, which represents the variation of the compressive strength against the UPV, indicates that the graph of the straight line rises from left to right, which means that the higher the UPV value, the greater the compressive strength of concrete. Furthermore, a regression analysis was employed to examine the relationship between the UPV test results and the compressive strength of the concrete cube in order to develop a formula that allows calculating that compressive strength based on the UPV test results.

The regression equation is: $y=-174.02+46.634 X$.

Where: $\mathrm{y}$ is the compressive strength of concrete cube $(\mathrm{MPa})$, and $\mathrm{X}$ the average value of the UPV test results.

Close examination of the two important conditions used for the assessment of the goodness of fit of the regression equation allows noting that $\mathrm{R}^{2}=87.1 \%$ and $\mathrm{P}=0.001$. When these two values are respectively comparable with $100 \%$ and 0.005 , it can be said that the equation is acceptable.

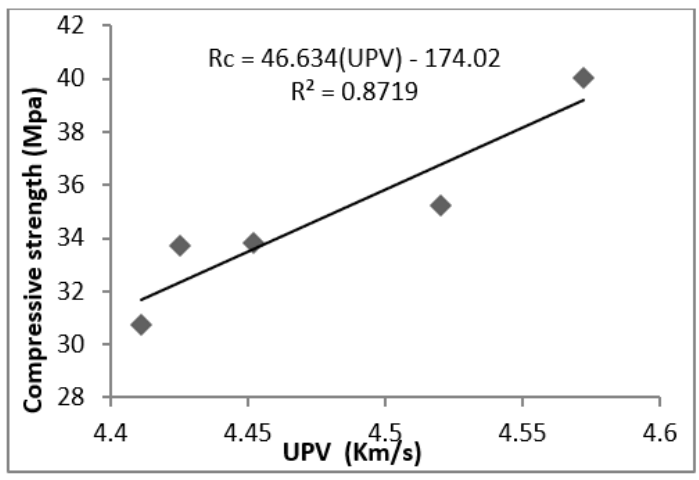

Figure 8. Relationship between the compressive strength and UPV

\subsection{Relationship between the compressive strength and rebound number}

The recorded experimental data were statistically analyzed to determine the best-fit correlation between the rebound number and compressive strength. In this context, Figure 9 shows the relationship between the rebound number $(\mathrm{RH})$ and compressive strength (Rc) of concrete containing marble powder. This same figure indicates that the rebound number and compressive strength are closely related [27].

It turned out that the compressive strength increased as the rebound number went up, for all types of concrete. It was therefore deemed more interesting to use a linear model for these types concrete. It should be noted that linear models are generally preferred by several researchers [4] because they are 
simple to use. Due to the heterogeneous nature of concrete, a general relationship between the rebound number and compressive strength, at the age of 28 days, could therefore be established based on the results presented in Figure 9, for all types of concrete. This same figure suggests that a very good linear relationship exists between the rebound number and compressive strength. It can indeed be said that $98 \%$ in the variation of the compressive strength values is accounted for its linear relationship with the rebound hammer number. The coefficient of determination $\mathrm{R}^{2}$ between these two quantities was found equal to 0.9845 . For all concrete types, the relationship between the compressive strength (Rc) and the rebound number $(\mathrm{RH})$ may be expressed as:

$$
\mathrm{Rc}=1.9951(\mathrm{RH})-30.157
$$

The above relation, between $\mathrm{Rc}$ and $\mathrm{RH}$, fits quite well the general form of the equation: $\mathrm{Rc}=\mathrm{a}(\mathrm{RH})+\mathrm{b}$ ), as was reported by Oke et al. [3].

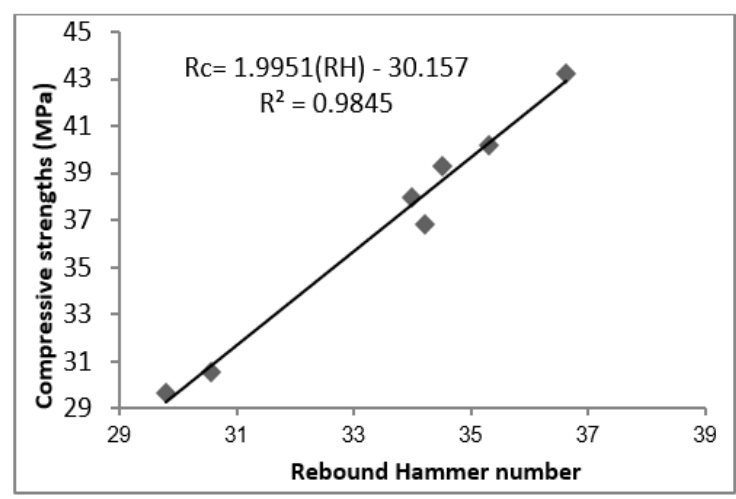

Figure 9. Correlation between the rebound number $(\mathrm{RH})$ and compressive strength $(\mathrm{Rc})$

\section{CONCLUSIONS}

Based on the experimental results, the following conclusions may be drawn:

- Incorporation of marble powder up to $10 \%$ in the concrete mixture enhanced the short and long term compressive strength of concrete. However, concrete including $15 \%$ to $30 \%$ of marble powder led to lower compressive strength values in comparison with that of control concrete;

- The non-destructive Schmidt rebound hammer test is recommended for assessing the compressive strength of concrete. This testing method was used to avoid the difficulties that are generally encountered while testing the compressive strength of concrete cubes in the case where different testing machines are used;

- The rebound number increased with concrete age because the hardness of concrete rises with age. The rebound hammer conversion diagram can therefore be used to determine the approximate compressive strength directly from the rebound number;

- Concrete mixture Mix2 exhibited optimal compressive strength and ultrasonic pulse velocity. These two quantities showed very low values for concrete containing various percentages of marble powder for early age curing, especially for samples including $25 \%$ and $30 \%$ of marble powder. However, as the curing period increased, both the compressive strength and UPV of the concrete samples augmented

- The compressive strength and UPV of concrete incorporating $20 \%$ MP were lower than that of control concrete. However, these values for Mix6 were smaller than that of Mix2, for all curing periods and for all replacement levels;

- The test results obtained for hardened concrete indicated that good correlations existed between the compressive strength, rebound number and ultrasonic pulse velocity. Moreover, the multiple regression analysis allowed observing that a better correlation existed between the different compressive strength values of all concrete samples; here the ultrasonic pulse velocity and rebound number were considered as independent variables.

\section{ACKNOWLEDGMENT}

The authors would like to express their acknowledgement for the help, support and encouragements that were provided by all those people who contributed to the preparation of the present work.

\section{REFERENCES}

[1] Hobbs, B., Kebir, M.T. (2007). Non-destructive testing techniques for the forensic engineering investigation of reinforced concrete buildings. Forensic Science International, $167(2-3)$ : 167-172. https://doi.org/10.1016/j.forsciint.2006.06.065

[2] Shariati, M., Ramli-Sulong, N.H., Arabnejad, M.M., Shafigh, P., Sinaei, H. (2011). Assessing the strength of reinforced concrete structures through Ultrasonic Pulse Velocity and Schmidt Rebound Hammer tests. Scientific Research and Essays, 6(1): 213-220. https://doi.org/10.5897/SRE10.879

[3] Oke, D.A., Oladiran, G.F., Raheem, R. (2017). Correlation between Destructive Compressive Testing (DT) and Non-Destructive Testing (NDT) for concrete strength. International Journal of Engineering Research and Science.

[4] Toubal Seghir, N., Benaimeche, O., Krzywiński, K., Sadowski, Ł. (2020). Ultrasonic evaluation of cementbased building materials modified using marble powder sourced from industrial wastes. Buildings, 10(3): 38 . https://doi.org/10.3390/buildings10030038

[5] Demirel, B., Alyamaç, K.E. (2018). Waste marble powder/dust. In: Waste and Supplementary Cementitions. Materials in Concrete, pp. 181-197. https://doi.org/10.1016/B978-0-08-102156-9.00006-7

[6] Tunc, E.T. (2019). Recycling of marble waste: A review based on strength of concrete containing marble waste. Journal of Environmental Management, 231: 86-97. https://doi.org/10.1016/j.jenvman.2018.10.034

[7] Chaid, R., Perrot, A., Ghernouti, Y. (2015). Durability of concretes with marble powder. In Proceedings of the 5th International Conference on Environment Science and Engineering, Istanbul, Turkey, pp. 24-25.

[8] Belouadah, M., Rahmouni, Z.E.A., Tebbal, N. (2019). Experimental characterization of ordinary concretes 
obtained by adding construction waste (glass, marble).

Procedia Computer Science, 158: 153-162. https://doi.org/10.1016/j.procs.2019.09.038

[9] Arel, H.Ş. (2016). Recyclability of waste marble in concrete production. Journal of Cleaner Production, 131: 179-188. https://doi.org/10.1016/j.jclepro.2016.05.052

[10] Rao, B.K. (2016). Study on marble powder as partial replacement of cement in normal compacting concrete. IOSR Journal of Mechanical and Civil Engineering (IOSR-JMCE), 13: 1-5.

[11] Toubal Seghir, N., Mellas, M., Sadowski, Ł., Krolicka, A., Żak, A., Ostrowski, K. (2019). The utilization of waste marble dust as a cement replacement in air-cured mortar. $\quad$ Sustainability, $11(8)$ : 2215. https://doi.org/10.3390/su11082215

[12] Technical data sheet. MEDAPLAST SP 40, Granitex, Algiers.

[13] NF EN 12390-5. (2012). French standard Tests for hardened concrete-Part 5: Flexural strength of the specimens.

[14] Tebbal, N., Rahmouni, Z.E.A. (2016). Influence of local sand on the physicomechanical comportment and durability of high performance concrete. Advances in Civil https://doi.org/10.1155/2016/3897064

[15] European Committee for Standartization EN 12504-2. (2003). Testing concrete in structures - Part 2: Nondestructive testing - Determination of rebound number.

[16] European Committee for Standartization EN 12309-3. (2003). Schmidt rebound hammer test gave values of. RN.

[17] Raju, S., Kumar, P.R. (2014). Effect of using glass powder in concrete. International Journal of Innovative Research in Science, Engineering and Technology, 31: 421-427.

[18] Celik, M.Y., Sabah, E. (2008). Marble deposits and the impact of marble waste on environmental pollution geological and technical characterization of Iscehisar (Afyon-Turkey). Journal of Environmental Management, 87(1): 106-116. https://doi.org/10.1016/j.jenvman.2007.01.004

[19] Abdullahi, M. (2012). Effect of aggregate type on compressive strength of concrete. International Journal of Civil \& Structural Engineering, 2(3): 791-800.

[20] Belouadah, M., Rahmouni, Z.E.A., Tebbal, N. (2018). Effects of glass powder on the characteristics of concrete subjected to high temperatures. Advances in Concrete Construction, $6(3)$ :

311 . https://doi.org/10.12989/acc.2018.6.3.311

[21] Idir, R. (2009). Mécanismes d'action des fines et des granulats de verre sur la réaction alcali-silice et la réaction pouzzolanique, Doctoral dissertation. Institut National des Sciences Appliquées de Toulouse.

[22] Lawrence, P. (2000). Sur l'activité des cendres volantes et des additions minérales chimiquement inertes dans les matériaux cimentaires. Doctoral dissertation, Thèse de doctorat de l'université Paul Sabatier, Toulouse III.

[23] Nobile, L. (2015). Prediction of concrete compressive strength by combined non-destructive methods. Meccanica, 50: 411-417 https://doi.org/10.1007/s11012014-9881-5

[24] Aguwamba, J.C., Adagba, T.A. (2012). Comparative analysis of the rebound hammer and ultrasonic pulse velocity in testing concrete. Nigerian Journal of Technology, 31(1): 31-39.

[25] Shariati, M., Ramli-Sulong, N.H., Arabnejad, M.M., Shafigh, P., Sinaei, H. (2011). Assessing the strength of reinforced concrete structures through Ultrasonic Pulse Velocity and Schmidt Rebound Hammer tests. Scientific Research and Essays, 6(1): 213-220. https://doi.org/10.1371/journal.pone.0015958

[26] Somna, R., Martnok, A., Horpibulsuk, S. (2016). Properties of concretes with natural and recycled coarse aggregates. Mahasarakham International Journal of

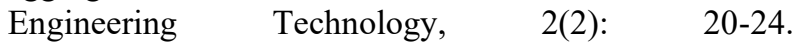
https://doi.org/10.14456/mijet.2016.11

[27] Atoyebi, O.D., Ayanrinde, O.P., Oluwafemi, J. (2019). Reliability comparison of Schmidt rebound hammer as a non-destructive test with compressive strength tests for different concrete mix. Journal of Physics: Conference Series, 1378(3): 032096. https://doi.org/10.1088/1742$6596 / 1378 / 3 / 032096$

\section{NOMENCLATURE}

$\begin{array}{ll}\text { CEM II/A } & \text { Portland cement type } \\ \text { MP } & \text { marble powder } \\ \text { UPV } & \text { ultrasonic pulse velocity } \\ \text { RH } & \text { rebound hammer } \\ \text { W/C } & \text { Water Cement Ratio } \\ \text { Rc } & \text { compressive strength }\end{array}$

\section{Greek symbols}

$\begin{array}{ll}\text { DS } & \text { dune sand } \\ \text { Gr } & \text { gravel } \\ \text { C } & \text { cement } \\ \text { W } & \text { water }\end{array}$

